\title{
Effects of tiaprofenic acid (Surgam) on cartilage proteoglycans in the rabbit joint immobilisation model
}

\author{
Isabelle Meyer-Carrive, Peter Ghosh
}

\begin{abstract}
A well established model of arthritis induced in rabbit knee joints by immobilisation in full extension for $\mathbf{3 0}$ days was used to evaluate the in vivo effects of $2 \cdot 5,5.0$, and $10.0 \mathrm{mg} / \mathrm{kg}$ body weight of tiaprofenic acid on articular cartilage proteoglycans. The drug was given subcutaneously every 24 hours during the entire immobilisation period. Immobilised animals not treated with drugs and normal animals were used as controls. In the non-drug treated immobilised animals articular cartilage showed evidence of surface damage accompanied by synovial hypertrophy and effusion. Proteoglycan concentrations were reduced in cartilages of these joints and the incorporation of ${ }^{35} \mathrm{SO}_{4}^{2-}$ into macromolecular proteoglycans was higher than in cartilages of non-immobilised controls. Gel filtration chromatographic studies of both resident and ${ }^{35} S$ labelled proteoglycans isolated from immobilised joint cartilage showed reduced aggregation and the presence of degraded proteoglycan subunit species. Whereas the administration of $10.0 \mathrm{mg} / \mathrm{kg}$ tiaprofenic acid every 24 hours to immobilised animals exacerbated the degradation and loss of proteoglycans from joint cartilages, $5.0 \mathrm{mg} / \mathrm{kg}$ tiaprofenic acid provided some protection of these macromolecules, as shown by the concentrations and extractability of proteoglycans from cartilages, which were comparable with those from non-immobilised controls. A high incorporation of ${ }^{35} \mathrm{~S}$ into proteoglycans was demonstrated, together with reduced catabolism of proteoglycans, indicating preservation of chondrocyte anabolic activity. At a tiaprofenic acid dose of $2.5 \mathrm{mg} / \mathrm{kg}$, however, no beneficial effects on cartilage proteoglycans could be shown.
\end{abstract}

Although the cause of osteoarthritis is presently unknown, there is general agreement ${ }^{1-3}$ that failure of articular cartilage represents an early and critical step in the progression of this disorder. Articular cartilage consists essentially of chondrocytes embedded in a hydrated gel of proteoglycans which are constrained by an integrated network of collagen fibrils. The macromolecular organisation of the cartilage extracellular matrix is complex and is still the subject of investigation, but it has been established that the entrapment of the hydrophilic proteoglycans within the collagen meshwork confers to cartilage its hydroelastic properties and ability to recover from com- pressive deformation. ${ }^{4}{ }^{5}$ Biochemical and histochemical studies of cartilage from osteoarthritic joints have shown that proteoglycans are lost from the matrix in the more advanced stages of the disease. ${ }^{6-8}$ The depletion of these macromolecules results in a decline in the resilience of the tissue, and the mechanical stresses transmitted across the joint may contribute to the progression of pathological changes in cartilage and subchondral bone.

Non-steroidal anti-inflammatory drugs (NSAIDs) are extensively used in the management of osteoarthritis, but there is continuing debate about their beneficial or adverse effects on cartilage integrity. ${ }^{9-11}$ Some laboratory and clinical evidence ${ }^{11-14}$ suggests that several of the older NSAIDs may suppress the biosynthesis of proteoglycans in cartilage, thereby accelerating its failure rate. On the other hand, other data indicate that the effect of certain NSAIDs on cartilage is innocuous at therapeutically used concentrations, ${ }^{15} 16$ or that these drugs may even provide a protective role by supporting macromolecule biosynthesis within joint tissues. ${ }^{15} 17$ These latter studies have generally focused on diclofenac, piroxicam, and tiaprofenic acid and, for the most part, have been confined to in vitro investigation.

In this study we considered the in vivo effects of various doses of tiaprofenic acid on cartilage proteoglycans in a rabbit experimental osteoarthritis. The results obtained indicated, in this model at least, that the loss or preservation of proteoglycans in articular cartilage is dependent on the amount of drug given.

\section{Materials and methods}

COMPOUNDS

Carrier free $\mathrm{H}_{2}{ }^{35} \mathrm{SO}_{4}$ (specific activity 1.6 $\mathrm{TBq} / \mathrm{mg}$ ) was obtained from Du Pont Medical Products (Wilmington, DE, USA). Guanidine hydrochloride (grade 1), trizma base (reagent grade (TRIS)), bovine serum albumin, phenylmethylsulphonyl fluoride, benzamidine hydrochloride, L-hydroxyproline, L-cysteine free base, D-glucuronolactone and hyaluronic acid (grade 1, from human umbilical cord), whale and shark chondroitin-4-sulphate and chondroitin-6-sulphate, Coomassie brilliant blue $G$, and calf thymus DNA were purchased from Sigma Chemical (St Louis, MO, USA). $N$ Ethylmaleimide was obtained from CalbiochemBehring Australia (Sydney, Australia), papain (papainase [EC 3.4.22.2] (puriss) from Fluka AG (Buchs, Switzerland), and Sepharose CL2B was supplied by Pharmacia (South Seas) (Sydney, Australia). All other chemicals and 
reagents were analytical grade or the highest grade available, unless specified.

\section{PROCEDURES}

Induction of cartilage degeneration in the rabbit knee joint by immobilisation

The experimental series comprised 31 mature (9-12 months old) New Zealand white rabbits. Rabbit joints were immobilised by a modification of published techniques. ${ }^{18} 19$ Briefly, two plastic concave splints $(220 \times 25 \times 2 \mathrm{~mm} ; 200 \times$ $20 \times 2 \mathrm{~mm}$ ) were used. The larger splint was applied to the ventral aspect of the left leg of the rabbits from the thigh to the distal end of the limb, which was maintained in full extension. The splint was attached to the limb by wrapping five turns of leucoplast bandage (Johnson and Johnson, Sydney, Australia) around the splint and leg. The second splint was similarly fixed but to the dorsal aspect of the limb. The tension in the bandage did not impair the blood supply to the leg. This procedure allowed $\pm 5^{\circ}$ of movement of the joint within the splint. The rabbits were allowed to move freely during the immobilisation period, checked daily, and the bandage replaced if damaged.

Drug administration and isotopic labelling of articular cartilage proteoglycans

The rabbits were treated prophylactically with $10 \cdot 0,5 \cdot 0$, or $2.5 \mathrm{mg} / \mathrm{kg}$ tiaprofenic acid during the entire immobilisation period. The drug as the trometamol salt injectable form (Roussel UCLAF, Sydney, Australia) was given subcutaneously every 24 hours over the 30 day immobilisation period, so that each animal received a total of 29 injections. Twenty four hours before they were killed the drug treated immobilised group, the immobilised group not treated with drugs, and the non-immobilised control group not treated with drugs were injected intravenously with $\mathrm{H}_{2}{ }^{35} \mathrm{SO}_{4}$ in physiological saline $(1.0 \mathrm{ml})(92.5 \mathrm{MBq} / \mathrm{kg})$ through the marginal ear vein. The animals were killed by an intravenous injection of sodium pentobarbitone $(75 \mathrm{mg} / \mathrm{kg})$ into the marginal ear vein.

\section{EXPERIMENTAL GROUPS EXAMINED}

The following groups were examined:

Group 1: nine rabbits that were not immobilised and did not receive any drug (external control group).

Group 2: nine rabbits with immobilised joints that received no drug during the experiment (non-drug treated immobilised joint group).

Group 3: the contralateral joints of the nine group 2 animals. Our previous experiments ${ }^{19}$ using this model had shown that the cartilage of contralateral joints was also influenced by the immobilisation procedure/(non-drug treated contralateral joint group).

Group 4: the immobilised joints of four rabbits that were given $10.0 \mathrm{mg} / \mathrm{kg}$ tiaprofenic acid subcutaneously every 24 hours throughout the immobilisation period $(10.0 \mathrm{mg}$ treated group).

Group 5: the contralateral joints of the four group 4 animals.
Group 6: the immobilised joints of six rabbits that received $5 \mathrm{mg} / \mathrm{kg}$ tiaprofenic acid subcutaneously every 24 hours during the immobilisation period ( $5.0 \mathrm{mg}$ treated group).

Group 7: the contralateral joints of the six group 6 animals.

Group 8: the immobilised joints of three rabbits given $2.5 \mathrm{mg} / \mathrm{kg}$ tiaprofenic acid subcutaneously during the immobilisation period ( $2.5 \mathrm{mg}$ treated group).

Group 9: the contralateral joints of the three group 8 animals.

\section{DISSECTION AND ANALYSIS OF TISSUES}

Rabbit joints were opened and the articular cartilage was removed from femoral condyles, suprapatellar groove, and tibial plateaux with a surgical blade. The cartilage from each of these regions was pooled, finely diced, transferred to preweighed stoppered tubes, and lyophilised. Aliquots of the pooled anhydrous cartilage were analysed for hexuronic acid content, after papain digestion ${ }^{20}$ by the method of Blumenkrantz and Asboe-Hansen, ${ }^{21}$ using glucuronolactone as a standard. The sulphated glycosaminoglycans of column fractions were measured by the methods of Farndale et $a l^{22}$ with chondroitin-6-sulphate as a standard. The radioactivity of proteoglycan samples, or column fractions, was determined by liquid scintillation spectrometry. All analyses were conducted in triplicate.

\section{EXTRACTION AND PURIFICATION OF} PROTEOGLYCANS

Proteoglycans were dissociatively extracted from aliquots of diced wet articular cartilage with 10 volumes of freshly prepared buffered $4 \mathrm{M}$ guanidine hydrochloride containing the protease inhibitors $25 \mathrm{mM}$ EDTA, $10 \mathrm{mM} \mathrm{N}$ ethylmaleimide, and $1 \mathrm{mM}$ benzamidine $\mathrm{HCl}$ in $50 \mathrm{mM}$ TRIS at $\mathrm{pH} 7 \cdot 4$ for 48 hours at $4^{\circ} \mathrm{C}$, as described by Oegema et al. ${ }^{23}$ After centrifugation $(20$ minutes at $2000 \mathrm{~g}$ ) the residues were washed twice with a small volume $(\sim 0.5 \mathrm{ml})$ of extraction buffer, and the supernatants and washings were pooled. The residues were washed thoroughly (48 hours extraction) with distilled water and lyophilised before papain digestion. ${ }^{20}$ The residues were analysed for hexuronic acid content, ${ }^{21}$ as described above. The percentage of proteoglycans extracted from the cartilage was calculated as the hexuronic acid content in the extract $\times 100 /$ total hexuronic acid concentrations in residues and extracts.

The $4 \mathrm{M}$ guanidine hydrochloride extracts were dialysed in the presence of hyaluronic acid ( $2 \%(w t / w t)$ of extract hexuronate content) overnight at $4^{\circ} \mathrm{C}$ against nine volumes $0.5 \mathrm{M}$ sodium acetate ( $\mathrm{pH} \mathrm{6.4)} \mathrm{containing} \mathrm{the} \mathrm{same}$ enzyme inhibitors as used for the extraction buffer, ${ }^{23}$ thereby reducing the guanidine hydrochloride concentration to $0.4 \mathrm{~mol} / 1 .{ }^{24} \mathrm{Solid} \mathrm{CsCl}$ was then added to produce a starting density of $1.6 \mathrm{~g} / \mathrm{ml}^{24}$ and the solution subjected to ultracentrifugation for 24 hours at $6^{\circ} \mathrm{C}$ at $50000 \mathrm{rpm}$ with a Sorval OTD65B centrifuge and TV-865B vertical rotor, as described previously. ${ }^{25}$ The 
centrifuge tubes were manually fractionated into six $700 \mu \mathrm{l}$ fractions with an automatic pipette, starting at the top of the tube. Aliquots of these fractions were analysed for protein by the bicinchoninic acid method ${ }^{26}$ and sulphated glycosaminoglycans by the method of Farndale et al. ${ }^{22}$ The density of the fractions was determined by weighing an aliquot of known volume. Ninety per cent of the proteoglycans were found in the bottom two fractions (density $\geqslant 1.65$ ). These were therefore combined and called the Al fractions, according to the terminology of Heinegård. ${ }^{27}$

SEPHAROSE CL-2B GEL CHROMATOGRAPHY

Aliquots of the Al fractions, which contained $40-100 \mu \mathrm{g}$ of hexuronic acid, were chromatographed on a Sepharose CL-2B column $(20 \times 1$ $\mathrm{cm})$, eluted with $0.5 \mathrm{M}$ sodium acetate $(\mathrm{pH}$ $6 \cdot 8)$. Flow through the column was $10 \mathrm{ml} / \mathrm{h}$, and the column was calibrated with highly polymerised DNA $\left(\mathrm{V}_{\mathrm{o}}\right), \mathrm{H}_{2}{ }^{35} \mathrm{SO}_{4}\left(\mathrm{~V}_{\mathrm{t}}\right)$, and a papain digested cartilage sample (chondroitin sulphate peptides). Fractions of $250 \mu \mathrm{l}$ were collected, $100 \mu \mathrm{l}$ aliquots counted for radioactivity (24 hour synthesised proteoglycans), and 10-100 $\mu \mathrm{l}$ aliquots were used to determine total sulphated glycosaminoglycans, using the method of Farndale et al. ${ }^{22}$

STATISTICAL ANALYSIS OF RESULTS

The data obtained were analysed either by a paired Student's $t$ test between groups of the same animals (immobilised and contralateral) or an unpaired Student's $t$ test between groups of different animals. Differences between groups were considered to be significant when $p \leqslant 0.05$.

\section{Results}

PROTEOGLYCAN CONTENT (AS HEXURONATE)

Figure 1 shows that the hexuronic acid content

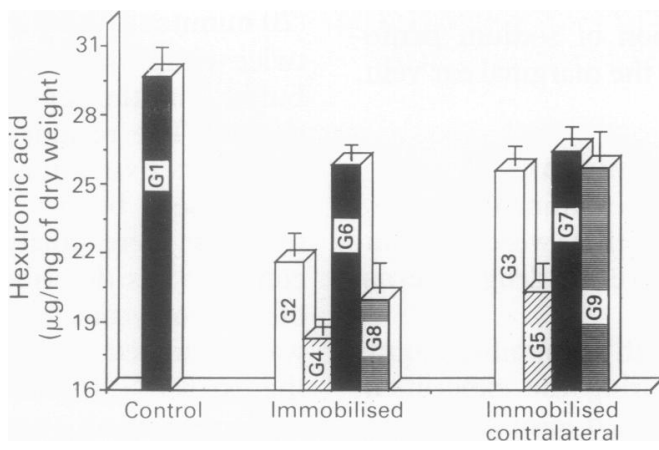

Figure I Mean (SEM) hexuronic acid concentration ( $\mathrm{g} / \mathrm{mg}$ dry weight) of rabbit knee joint articular cartilage from normal $(G 1)$; immobilised (G2): contralateral to immobilised (G3); immobilised and drug treated ( $10 \mathrm{mg} / \mathrm{kg})(\mathrm{G} 4)$; contralateral joint to $G 4(G 5)$ immobilised and drug treated $(\square: 5 \mathrm{mg} / \mathrm{kg})(G 6)$ contralateral joint to $G 6(G 7)$; immobilised and drug treated (․ㅡㄹ. $2.5 \mathrm{mg} / \mathrm{kg})(G 8)$; contralateral joint to $G 8(G 9)$ animals. Significant differences found between groups were: $G 1>G 2$ $(p \leqslant 0.0005) ; G 1>G 3(p \leqslant 0.005)$;

$G 1>G 4(p \leqslant 0.0005) ; G 1>G 5(p \leqslant 0.0005)$

$G 1>G 6(p \leqslant 0.01) ; G 1>G 7(p \leqslant 0.025)$

$G 1>G 8(p \leqslant 0.0005) ; G 1>G 9(p \leqslant 0.05) ; G 2<G 3$

$(p \leqslant 0.005) ; G 2>G 4(p \leqslant 0.0005)$

$G 2<G 6(p \leqslant 0.005) ; G 3>G 5(p \leqslant 0.005)$

$G 5>G 4(p \leqslant 0.025) ; G 9>G 8(p \leqslant 0.025)$. of articular cartilage of the non-drug treated immobilised joints (group 2) was significantly lower than that of the contralateral joints (group 3) $(p \leqslant 0.0005)$ and that of the non-immobilised controls (group 1) $(p \leqslant 0.0005)$. The hexuronate content of the cartilages of the contralateral free joints of the immobilised animals (group 3) was also significantly lower $(p \leqslant 0.005)$ than that of the non-immobilised control (group 1) animals.

The loss of proteoglycans from the knee joint articular cartilage of immobilised joints was enhanced when animals were given $10 \mathrm{mg} / \mathrm{kg}$ tiaprofenic acid (group 4). This loss was significantly greater than for the group 2 joints $(p \leqslant 0.0005)$. Similarly, the contralateral joint cartilage values (group 5) were significantly lower than those for the non-drug treated control group (group 3$)(p \leqslant 0.0005)$.

In contrast with the animals who received 10 $\mathrm{mg} / \mathrm{kg}$ tiaprofenic acid, the hexuronate concentrations in cartilages of animals receiving 5.0 $\mathrm{mg} / \mathrm{kg}$ tiaprofenic acid (groups 6 and 7) were higher than those found in cartilages of the nondrug treated immobilised groups (groups 2 and 3 ). These differences were significant at the $p \leqslant 0.005$ level (fig 1). On the other hand, the hexuronate concentrations in cartilages of immobilised animals treated with $2.5 \mathrm{mg} / \mathrm{kg}$ tiaprofenic acid (groups 8 and 9) were indistinguishable statistically from values in non-drug treated controls (groups 2 and 3).

\section{PROTEOGLYCAN EXTRACTABILITY}

The proportion of proteoglycans extracted from cartilages of non-drug treated immobilised and contralateral joints (groups 2 and 3 ) was significantly lower than that of the corresponding non-immobilised controls (group 1) $(p \leqslant 0.0005 ; p \leqslant 0.005$ respectively) (fig 2 ). Apart from cartilages of animals receiving $5.0 \mathrm{mg} / \mathrm{kg}$ tiaprofenic acid, the proportion of proteoglycans extracted from groups $4,8,5$, and 9 was similar to that from the non-drug treated immobilised groups (groups 2 and 3 ) (fig 2).

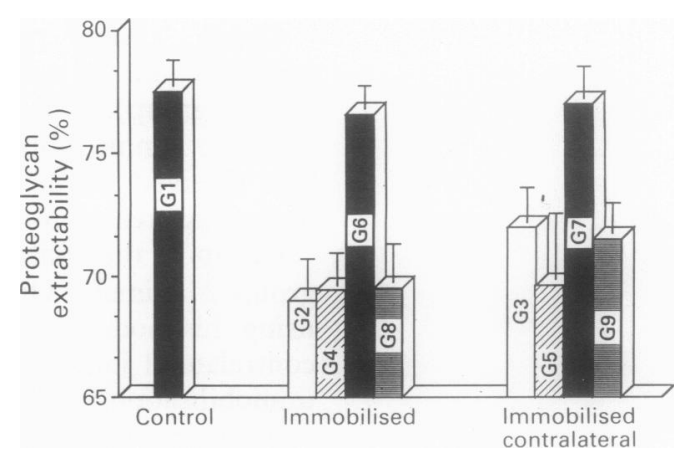

Figure 2 Mean (SEM) percentage extractability of proteoglycans $(4 \cdot 0 \mathrm{M}$ guanidine hydrochloride from rabbit knee joint cartilages. Group coding as for fig 1. Significant differences found between groups were: $G 1>G 2$ $(p \leqslant 0.0005) ; G 1>G 3(p \leqslant 0.005)$;

$G 1>G 4(p \leqslant 0.005) ; G 1>G 5(p \leqslant 0.0005)$

$G 1>G 8(p \leqslant 0.005) ; G 1>G 9(p \leqslant 0.005) ; G 2<G 3$

$(p \leqslant 0.005) ; G 2<G 6(p \leqslant 0.005) ; G 3<G 7(p \leqslant 0.025)$. 
${ }^{35} S$ LABELLED PROTEOGLYCAN SPECIFIC ACTIVITY Figure 3 shows the specific activity of ${ }^{35} \mathrm{~S}$ labelled proteoglycans isolated from joint cartilages of normal and experimental animals. Joint immobilisation increased the incorporation of ${ }^{35} \mathrm{~S}$ into the extractable proteoglycans by about $50 \%$ of the control values (group $1 v$ group 2) $(\mathrm{p}<0.005)$. Treatment with $10 \mathrm{mg} / \mathrm{kg}$ tiaprofenic acid decreased the incorporation of ${ }^{35}$ S into proteoglycans to within non-immobilised control levels (group 1), but animals given 5 $\mathrm{mg} / \mathrm{kg}$ of the drug (groups 6 and 7) showed enhanced biosynthetic activity in both immobilised and contralateral joints, as shown by the higher specific activity value of isolated proteoglycans (fig 3).

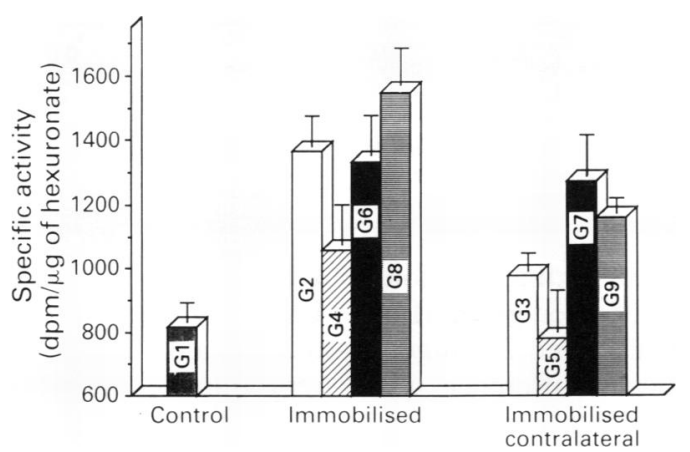

Figure 3 Mean (SEM) specific activity (as dpm/ $\mathrm{gg}$ hexuronate of ${ }^{35} S$ labelled proteoglycans isolated from rabbit knee joint articular cartilages. Group coding as for fig 1. Significant differences found between groups were: $G 1<G 2(p \leqslant 0.0005) ; G 1<G 3(p \leqslant 0.05) ; G 1<G 4$ $(p \leqslant 0.05) ; G l<G 6(p \leqslant 0.005) ; G l<G 7$

$(p \leqslant 0.005) ; G l<G 8(p \leqslant 0.0005) ; G 1<G 9$

$(p \leqslant 0.05) ; G 2>G 3(p \leqslant 0.05) ; G 2>G 4$

$(p \leqslant 0.05) ; G 3<G 7(p<0.025) ; G 3<G 9(p<0.05)$; $G 5<G 4(p \leqslant 0.05) ; G 9<G 8(p<0.05)$.
SEPHAROSE CL-2B CHROMATOGRAPHY AND

HYALURONIC ACID BINDING STUDIES

Figures 4 and 5 show the chromatographic profiles of the resident proteoglycans as determined by the assay of Farndale et $a l,{ }^{22}$ and newly synthesised proteoglycans, as measured by ${ }^{35} \mathrm{~S}$ radioactivity, from the cartilage of normal and experimental animals. Whereas the polydispersity and extent of aggregation of the newly synthesised $\left({ }^{35} \mathrm{~S}\right.$ labelled proteoglycans) and resident populations of proteoglycans were similar in normal cartilage (figs $4 \mathrm{~A}$ and $5 \mathrm{~A}$ ), the proteoglycans isolated from the cartilage of immobilised joints (including contralateral joints), showed decreased aggregation for both resident and newly synthesised species (figs 4B and $5 \mathrm{~B}$ ). The aggregation was significantly lower than in group $1(p \leqslant 0.0005)$ (table). Moreover, the hydrodynamic range of the proteoglycans isolated from the immobilised cartilage was markedly altered, a major population eluting with $\mathrm{K}_{\mathrm{av}}$ values similar to those of the chondroitin sulphate peptides $\left(\mathrm{K}_{\mathrm{av}} \sim 0.85\right)$ (figs 4B and 5B, table).

Proteoglycans isolated from the cartilage of animals given $10 \mathrm{mg} / \mathrm{kg}$ tiaprofenic acid showed similar aggregation characteristics to those of the proteoglycans of the immobilised but nondrug treated controls. The non-aggregatable proteoglycan population, however, was of overall smaller hydrodynamic size (figs $4 \mathrm{C}$ and $5 \mathrm{C})$. On the other hand, the proteoglycans extracted from the cartilage of immobilised animals given $5 \mathrm{mg} / \mathrm{kg}$ tiaprofenic acid showed aggregation characteristics which were comparable with those of proteoglycans isolated from the non-immobilised control cartilage (figs 4D and 5D, table). In addition, the polydispersity of the included proteoglycan species, although not identical to that of the controls,
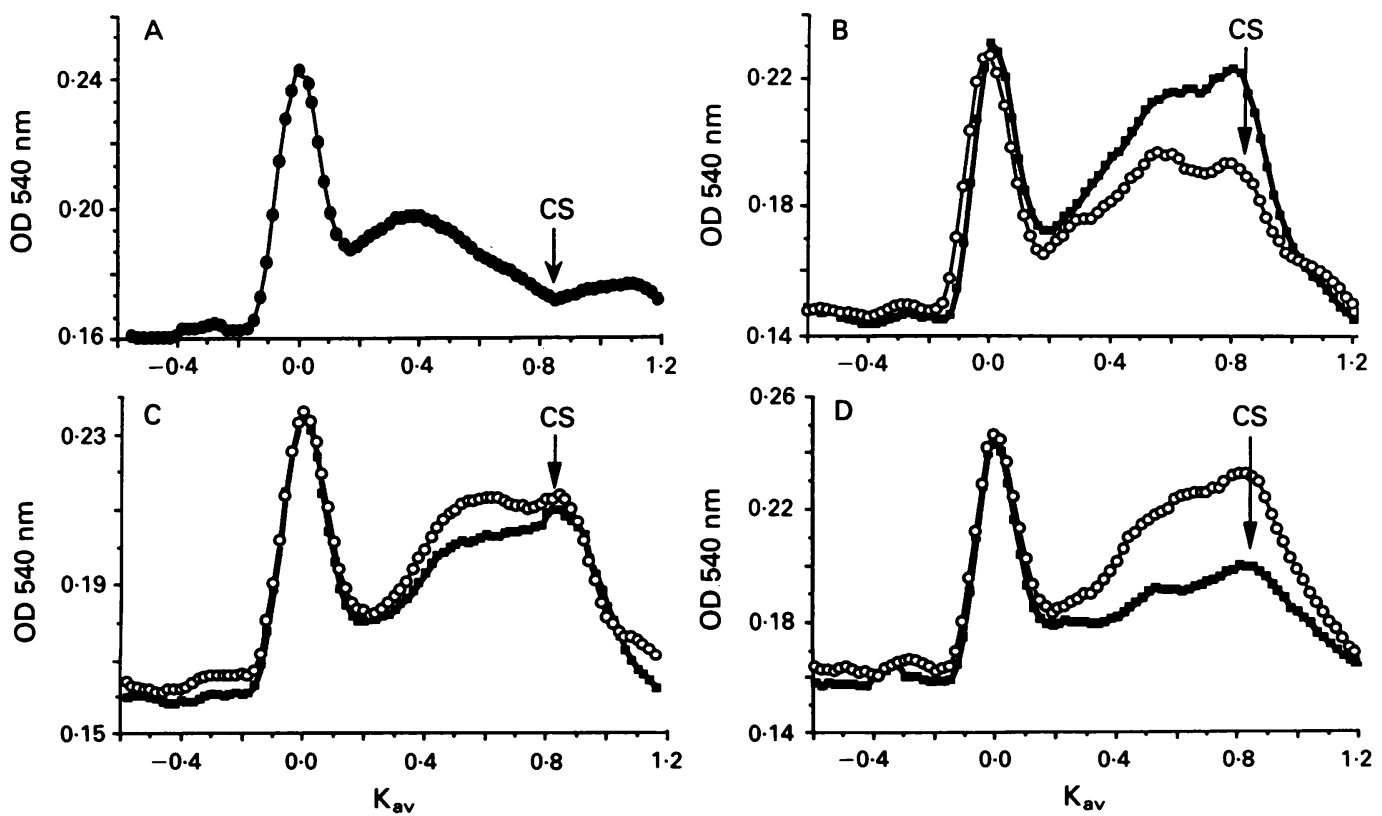

Figure 4 Sepharose CL-2B chromatograms of resident proteoglycans (as Farndale et al ${ }^{22}$ positive material) isolated from rabbit knee joint cartilages of $(A)$ non-immobilised non-drug treated animals; $(B)$ immobilised $(\square)$ and contralateral $(\mathrm{O}-\mathrm{O})$ of non-drug treated animals; $(C)$ immobilised $\left(\mathrm{C}_{-}\right)$and contralateral $(\mathrm{O}-\mathrm{O})$ of animals treated with $10.0 \mathrm{mg} / \mathrm{kg}$ of tiaprofenic acid; and $(D)$ immobilised $(\square-\square)$ and contralateral $(\mathrm{O}-\mathrm{O})$ of animals treated with $5.0 \mathrm{mg} / \mathrm{kg}$ tiaprofenic acid. CS represent the elution position of chondroitin sulphate peptides. $\left(K_{u v}=0 \cdot 85\right)$. 

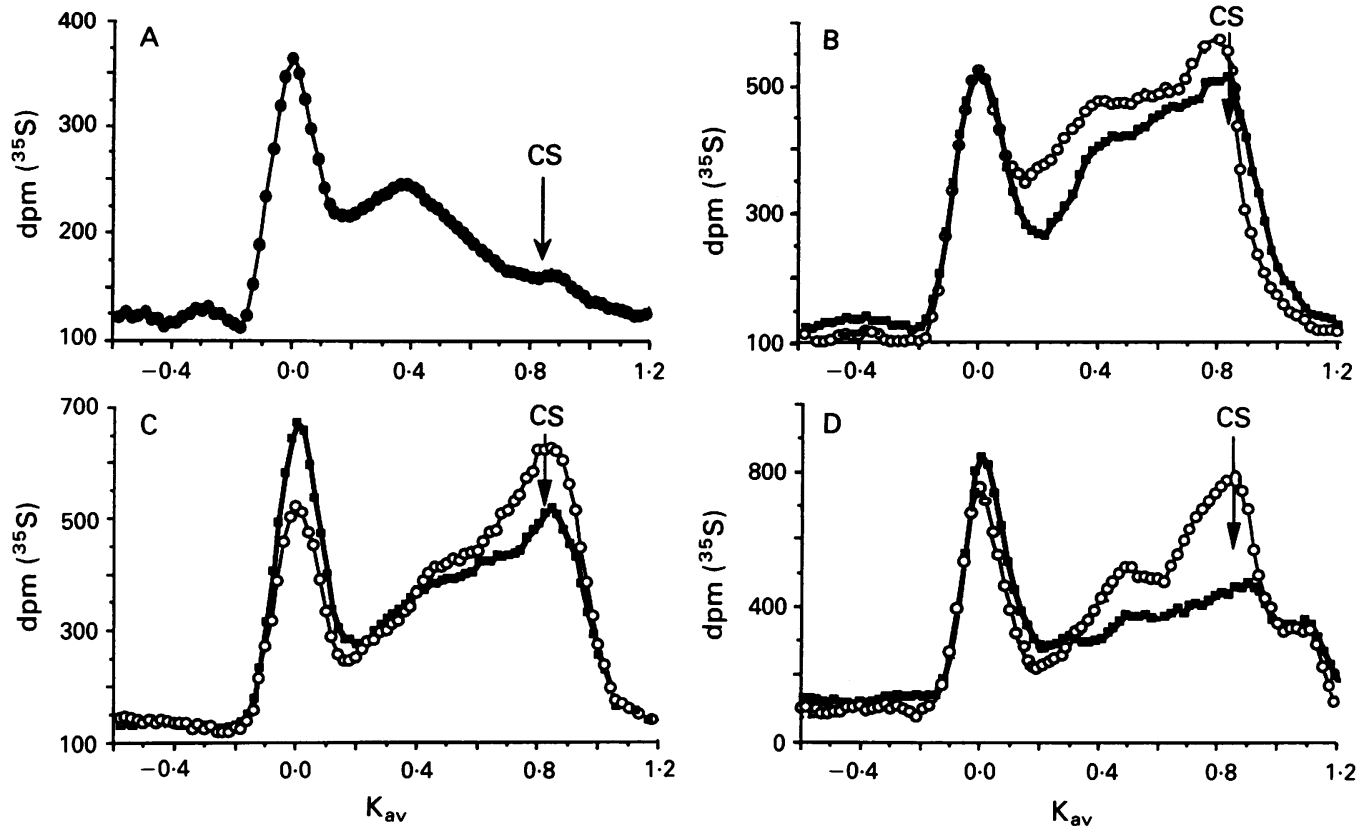

Figure 5 Sepharose $C L-2 B$ chromatogram of ${ }^{35}$ S labelled proteoglycans isolated from rabbit knee joint cartilages. $P$ anels and symbols identical to those used in fig 4.

was much less than the corresponding fractions of the non-drug treated immobilised group (figs 4 and 5 , table). With animals given $2.5 \mathrm{mg} / \mathrm{kg}$ tiaprofenic acid no significant difference was found relative to the non-drug treated immobilised groups (data not shown).
Discussion

Using a modification of the immobilisation technique of Langenskiold $e t a l,{ }^{18}$ we induced reproducible changes in the articular cartilage and periarticular structures of rabbit joints after four weeks. The morphological changes seen

Aggregation (as percentage of total) of resident and newly synthesised proteoglycans isolated from rabbit joint articular cartilages

\begin{tabular}{|c|c|c|c|c|c|}
\hline \multirow[t]{2}{*}{ Regimen } & \multirow[t]{2}{*}{ Group } & \multicolumn{2}{|c|}{${ }^{35} S$ labelled proteoglycans (dpm) } & \multicolumn{2}{|c|}{ Resident proteoglycans } \\
\hline & & Mean (SEM) & $\begin{array}{l}\text { Significant difference } \\
\text { between groups }\end{array}$ & Mean (SEM) & $\begin{array}{l}\text { Significant difference } \\
\text { between groups }\end{array}$ \\
\hline Non-immobilised control $(n=9)$ & 1 & $40.4(0.63)$ & & $41 \cdot 7(0 \cdot 9)$ & \\
\hline $\begin{array}{l}\text { Non-drug treated immobilised } \\
\text { joint }(n=9)\end{array}$ & 2 & $31 \cdot 3(2 \cdot 0)$ & $\begin{array}{l}\mathrm{Gl}>\mathrm{G} 2 \\
(\mathrm{p} \leqslant 0 \cdot 0005)\end{array}$ & $27 \cdot 5(1 \cdot 8)$ & $\begin{array}{l}\mathrm{Gl}>\mathrm{G} 2 \\
(\mathrm{p} \leqslant 0.0005)\end{array}$ \\
\hline $\begin{array}{l}\text { Non-drug treated contralaterai } \\
\text { joint }(n=9)\end{array}$ & 3 & $23 \cdot 9(2 \cdot 8)$ & $\begin{array}{l}\mathrm{Gl}>\mathrm{G3} \\
(\mathrm{p} \leqslant 0.0005) \\
\mathrm{G} 3<\mathrm{G} 2 \\
(\mathrm{p} \leqslant 0.05)\end{array}$ & $36 \cdot 0(1 \cdot 5)$ & $\begin{array}{l}G 1>G 3 \\
(p \leqslant 0.005) \\
G 3>G 2 \\
(p \leqslant 0.005)\end{array}$ \\
\hline $\begin{array}{l}\text { Treated tiaprofenic acid } \\
10 \mathrm{mg} / \mathrm{kg} \text { immobilised } \\
\text { joint }(\mathrm{n}=4)\end{array}$ & 4 & $37 \cdot 1(1 \cdot 0)$ & $\begin{array}{l}\mathrm{Gl}>\mathrm{G} 4 \\
(\mathrm{p} \leqslant 0 \cdot 025) \\
\mathrm{G} 4 \text { NSD G2 }\end{array}$ & $31 \cdot 4(1 \cdot 7)$ & $\begin{array}{l}\mathrm{G} 1>\mathrm{G} 4 \\
(\mathrm{p} \leqslant 0 \cdot 0005) \\
\mathrm{G} 4 \text { NSD G2 }\end{array}$ \\
\hline $\begin{array}{l}\text { Treated tiaprofenic acid } \\
10 \mathrm{mg} / \mathrm{kg} \text { contralateral } \\
\text { joint }(\mathrm{n}=4)\end{array}$ & 5 & $29 \cdot 7(1 \cdot 2)$ & $\begin{array}{l}G 1>G 5 \\
(p \leqslant 0 \cdot 0005) \\
\text { G5 NSD G3 } \\
\text { G5 }<\text { G4 } \\
(p \leqslant 0 \cdot 05)\end{array}$ & $32 \cdot 5(1 \cdot 7)$ & $\begin{array}{l}\text { G1 > G5 } \\
\text { G5 NSD G3 } \\
\text { G5 NSD G4 }\end{array}$ \\
\hline $\begin{array}{l}\text { Treated tiaprofenic acid } \\
5 \mathrm{mg} / \mathrm{kg} \text { immobilised } \\
\text { joint }(\mathrm{n}=6)\end{array}$ & 6 & $41 \cdot 6(1 \cdot 6)$ & $\begin{array}{l}\text { G1 NSD G6 } \\
\text { G6>G2 } \\
(p \leqslant 0 \cdot 005)\end{array}$ & $42 \cdot 0(1 \cdot 0)$ & $\begin{array}{l}\text { G1 NSD G6 } \\
\text { G6>G2 } \\
(p \leqslant 0 \cdot 0005)\end{array}$ \\
\hline $\begin{array}{l}\text { Treated tiaprofenic acid } \\
5 \mathrm{mg} / \mathrm{kg} \text { contralateral } \\
\text { joint }(\mathrm{n}=6)\end{array}$ & 7 & $30 \cdot 3(1 \cdot 8)$ & $\begin{array}{l}\text { Gl }>G 7 \\
(p \leqslant 0.0005) \\
\text { G7 }>\text { G3 } \\
(p \leqslant 0.05) \\
G 7<G 6 \\
(p \leqslant 0.025)\end{array}$ & $34 \cdot 2(1 \cdot 0)$ & $\begin{array}{l}\text { G1 }>\text { G7 } \\
(p \leqslant 0 \cdot 0005) \\
\text { G7 NSD G3 } \\
\text { G7 }<G 6 \\
(p \leqslant 0 \cdot 01)\end{array}$ \\
\hline $\begin{array}{l}\text { Treated tiaprofenic acid } \\
2.5 \mathrm{mg} / \mathrm{kg} \text { immobilised } \\
\text { joint }(\mathrm{n}=3)\end{array}$ & 8 & $34 \cdot 6(1 \cdot 0)$ & $\begin{array}{l}\mathrm{G} 1>\mathrm{G} 8 \\
(p \leqslant 0 \cdot 005) \\
\text { G8 NSD G2 }\end{array}$ & $29 \cdot 5(2 \cdot 2)$ & $\begin{array}{l}\mathrm{G} 1>\mathrm{G} 8 \\
(\mathrm{p} \leqslant 0 \cdot 0005) \\
\text { G8 NSD G2 }\end{array}$ \\
\hline $\begin{array}{l}\text { Treated tiaprofenic acid } \\
2.5 \mathrm{mg} / \mathrm{kg} \text { contralateral } \\
\text { joint }(\mathrm{n}=3)\end{array}$ & 9 & $26 \cdot 5(1 \cdot 2)$ & $\begin{array}{l}\text { G1 }>\text { G9 } \\
(p \leqslant 0 \cdot 0005) \\
\text { G9 NSD G3 } \\
\text { G9 }<\text { G8 } \\
(p \leqslant 0.01)\end{array}$ & $34 \cdot 9(1 \cdot 7)$ & $\begin{array}{l}G 1>G 9 \\
(p \leqslant 0 \cdot 005) \\
G 8 \text { NSD G2 }\end{array}$ \\
\hline
\end{tabular}

${ }^{*}$ Farndale et al. 22 
were decreased lustre of the cartilage surface with some pitting, subchondral hyperaemia, thickening of the synovium, and increased synovial effusions (data not shown). Similar changes have been described by others. ${ }^{18} 28-32$ It has been reported that proliferation of synovial lining cells and infiltration of mononuclear cells occurs within a week of immobilisation of rabbit joints. ${ }^{32}$ This is then followed by cartilage surface changes, softening, and chondrocyte proliferation at the joint margins accompanied by subchondral changes. ${ }^{18} \quad 28-32$

We found that the cartilage of the immobilised joints contained a reduced amount of proteoglycans, which were less extractable. From the gel filtration studies, this seems to be due to their enhanced catabolism both at the hyaluronate binding region and the chondroitin sulphate-rich regions of the proteoglycan core protein. This was evident from the reduced ability of proteoglycans to form aggregates in the presence of hyaluronic acid (table) and the inclusion of degraded non-aggregating proteoglycan products into the Sepharose CL-2B gel (figs 4 and 5). It was noteworthy that this increased breakdown of proteoglycans occurred in cartilages of both immobilised and contralateral joints; this was particularly true for the newly synthesised ${ }^{35} \mathrm{~S}$ labelled proteoglycans (fig 5). We assume that this situation arises from the overall impairment of movement incurred by the immobilised limb, which introduces abnormal mechanical stresses across the contralateral joint of the animal. The finding of increased incorporation of ${ }^{35} \mathrm{~S}$ into proteoglycans of cartilage of immobilised rabbit joints was consistent with the report of Videman et $a{ }^{33}$ Although this indicates an increased metabolic response by chondrocytes to the depletion of proteoglycans from the extracellular matrix, similar changes do not occur in the cartilage of immobilised sheep ${ }^{34}$ or in canine joints, ${ }^{35}$ suggesting that the reaction of rabbit cartilage to immobilisation may be more severe than in other species.

Administration of $10.0 \mathrm{mg} / \mathrm{kg}$ tiaprofenic acid to the rabbits over the entire immobilisation period resulted in a marked depression in proteoglycan biosynthesis to joint cartilages (fig 3), accompanied by a loss of these macromolecules from the matrix (figs 4 and 5). The hydrodynamic size and polydispersity of the proteoglycans isolated were again consistent with proteolytic cleavage of proteoglycan core protein at the hyaluronate binding and the chondroitin sulphate-rich region (figs 4 and 5). Diclofenac when given orally at $1.5 \mathrm{mg} / \mathrm{kg}$ over 17 days in the same animal model as used here was also found to exacerbate the loss of proteoglycans (measured as glycosaminoglycans) from immobilised joint cartilage. ${ }^{36}$ In this study, however, the ${ }^{35} \mathrm{~S}$ radiolabelling experiments showed that proteoglycan biosynthesis was not altered by administration of the drug. In another study $^{37}$ indomethacin when given intraperitonally at $10 \mathrm{mg} / \mathrm{kg}$ to immobilised rabbits for 17 days did not increase the loss of proteoglycans from immobilised joint cartilages.

In view of these data it was therefore of some interest to find that when the dose of tiaprofenic acid given to rabbits in this model was reduced to $5.0 \mathrm{mg} / \mathrm{kg}$ the proteoglycans in the cartilage of immobilised joints were protected. Furthermore, from the ${ }^{35} \mathrm{~S}$ specific activity and chromatography studies it was clear that suppression of proteoglycan biosynthesis by the drug at this dose did not occur. In fact, the incorporation of ${ }^{35} \mathrm{~S}$ into the newly synthesised population was higher than in the non-drug treated immobilised controls (fig 3). At a dose of $2.5 \mathrm{mg} / \mathrm{kg}$ tiaprofenic acid failed to influence positively the loss of proteoglycans from cartilage of immobilised joints. Although we had chosen a prophylactic drug protocol, it is likely, on the basis of other investigations using osteoarthritic cartilage $^{3839}$ and a sheep model of osteoarthritis, ${ }^{40}$ that tiaprofenic acid is also effective once cartilage damage has started.

The only other drugs reported to show a protective effect on articular cartilage in this animal model were pentosan polysulphate (Cartrophen $)^{19}$ and glycosaminoglycan polysulphate (Arteparon): ${ }^{41}$ These agents are not NSAIDs, however, but oversulphated polysaccharides and were effective at $10 \mathrm{mg} / \mathrm{kg}$ but not $5 \mathrm{mg} / \mathrm{kg}$ when given intramuscularly over the four week immobilisation period. ${ }^{19} 41$ It should be noted that both these polysulphated polysaccharides have shown useful antiarthritic activities when used in other animal models as well as clinically. ${ }^{42} 43$

Tiaprofenic acid is a potent inhibitor of prostaglandin synthetase, being twice as active as indomethacin or diclofenac in the bovine seminal vesicle assay. ${ }^{44}$ Measurement of prostaglandin $\mathrm{E}_{2}$ concentrations and phospholipase $A_{2}$ in synovial fluids of patients with rheumatoid arthritis before and after oral treatment with tiaprofenic acid has confirmed that prostaglandin activity can be suppressed by this drug in human tissues. ${ }^{45} 46$ Furthermore, the catabolism of human osteoarthritic cartilage maintained in culture was shown to be reduced when tiaprofenic acid at $2.6 \mu \mathrm{g} / \mathrm{ml}$ was incorporated into the medium. ${ }^{38} 39$ As this effect could be ameliorated by addition of prostaglandin $\mathrm{E}_{2}$ or dibutyl cyclic AMP to the drug treated cultures it was suggested ${ }^{39}$ that tiaprofenic acid suppresses prostaglandin $E_{2}$ and cyclic AMP synthesis by chondrocytes. These studies led us to suggest that administration of $5 \mathrm{mg} / \mathrm{kg}$ tiaprofenic acid in the rabbit osteoarthritis model might achieve tissue concentrations able to modulate the biosynthesis of prostaglandin $E_{2}$ and cyclic AMP by both synovial cells and chondrocytes. As it is known that prostaglandin $\mathrm{E}_{2}$ and cyclic AMP stimulate the production of lymphokines ${ }^{47}$ and metalloproteinase ${ }^{48}$ by chondrocytes and synovial cells it would be reasonable to assume that the reduced catabolism of cartilage proteoglycans in immobilised joints in the presence of tiaprofenic acid proceeds through such pathways.

Several independent investigations have shown that arachidonic acid metabolites, including prostaglandin $\mathrm{E}_{2}$, can regulate interleukin $1,4749-50$ tumour necrosis factor, ${ }^{51} 52$ and superoxide free radical ${ }^{53}$ activity in inflammatory cells, and it has been suggested that blockade of prostaglandin $E_{2}$ synthesis by 
NSAIDs may promote, through a feedback loop, the production of interleukin 1 by chondrocytes. ${ }^{54}$ In addition, it has recently been shown $^{55}$ that the strong inhibitor of prostaglandin $\mathrm{E}_{2}$ biosynthesis, piroxicam, when used at $5 \mathrm{mg} / \mathrm{kg}$ in mice, enhanced lymphocyte proliferation and production of lymphokines in mononuclear phagocytes. Taken together, these studies strongly suggest that NSAIDs can both inhibit the production of proinflammatory prostaglandins and stimulate aspects of the immune response, such as the production of interleukin 1 and other cytokines.

We have formulated a working hypothesis to explain the results obtained in this study. We suggest that the inhibition of proteoglycan synthesis and enhanced catabolism of proteoglycans obtained in immobilised rabbit joints after administration of high dose tiaprofenic acid $(10 \mathrm{mg} / \mathrm{kg})$ arise from the effect of interleukin 1 and, possibly, tumour necrosis factor and superoxide radicals on the function of chondrocytes. Such mediators, particularly interleukin 1, are known to inhibit proteoglycan and collagen biosynthesis by chondrocytes ${ }^{56} 58$ and promote matrix component degradation either directly, or through the release of metalloproteinases. It is further proposed that interleukin 1 and other mediators are increased through the feed back loop ${ }^{51-54}$ which arises as a consequence of the strong suppression of prostaglandin $\mathrm{E}$ synthesis (including antiinflammatory prostaglandin $\mathrm{E}_{1}$ ) by tiaprofenic acid when used in rabbits at high concentration $(10 \mathrm{mg} / \mathrm{kg}$ ). On the other hand, at the lower dose of $5.0 \mathrm{mg} / \mathrm{kg}$ tiaprofenic acid, prostaglandin $E_{1}$ and $E_{2}$ activity in immobilised joints, while modulated, is not repressed to the extent that interleukin 1 activity is enhanced or the useful effects of prostaglandin $\mathrm{E}_{1}$ abolished. Hence catabolic processes are controlled but chondrocyte anabolic activity is not compromised. This proposal is at present highly speculative, but experiments are in progress to test its validity.

Despite our limited knowledge of the dose dependent mechanism of action of tiaprofenic acid in vivo it is clear from the present studies that this NSAID, in contrast with aspirin, ${ }^{59}$ diclofenac, ${ }^{36}$ and indomethacin, ${ }^{37}$ can protect articular cartilage in this animal model of arthritis when used at an appropriate dose. In this regard it is noteworthy that our pharmacokinetic studies have shown that tiaprofenic acid at $5.0 \mathrm{mg} / \mathrm{kg}$ given subcutaneously in the rabbit achieved peak serum concentrations of 25-30 $\mu \mathrm{g} / \mathrm{ml}$ (Meyer-Carrive I et al, unpublished data) which was comparable with the concentration found in man after daily oral administration of $600 \mathrm{mg}$ of this drug. ${ }^{60}$

We thank Ms Lynne Campbell for her assistance in preparing this manuscript, Dr Arthur Bolt for valuable discussions on the animal experiments, Ms Fiona Brook for her help with animal handling, and Ms Anne Darvodelsky in assisting with the proteoglycan aggregation studies. We also acknowledge with thanks financial support for this project, in the form of a postgraduate scholarship to Isabelle Meyer-Carrive, from Roussel UCLAF Australia Pty Limited.

1 McDevitt C A, Gilbertson E M, Muir H. An experimental model of osteoarthritis: early morphological and bio-
chemical changes. $\mathcal{F}$ Bone foint Surg [Br] 1977; 59: 24-35.
2 Thompson R C Jr, Oegema T R Jr. Metabolic activity of articular cartilage in osteoarthritis. $\mathcal{f}$ Bone foint Surg [Am] 1979; 61: 407-16.

3 Fassbender $H$ G. Joint destruction in various arthritic disease. In: Kuettner K E, Schleyerback R, Hascall V-C, disease. In: Kuettner K E, Schleyerback R, Hascall V-C,
eds. Articular cartilage biochemistry. New York: Raven eds. Articular carila
Press, 1986: 371 .

4 Kempson G E, Muir M, Swanson S A V, et al. Correlations between the stiffness and the chemical constituents of cartilage on the human femoral head. Biochim Biophys Acta 1970; 215: 70-7.

5 Maroudas A, Ziu L, Weisman N, Venn M F. Studies of hydration and swelling pressure in normal and osteoarthritic cartilages. Biorheology 1985; 22: 87-122.

6 Mankin H J, Lippiello L. Biochemical and metabolic abnormalities in articular cartilage from osteo-arthrotic human hips. F Bone foint Surg [Am] 1970; 52: 424-34.

7 Sweet M B E, Thonar E J-M A, Immelman A R, Solomon L. Biochemical changes in progressive osteoarthrosis. Ann Rheum Dis 1977; 36: 387-98.

8 Poole A R. Changes in the collagen and proteoglycan of articular cartilage in arthritis. Rheumatology 1986; 10: 316-71.

9 Doherty $M$. Chondroprotection by non-steroidal antiinflammatory drugs. Ann Rheum Dis 1989; 48: 619-21.

10 Ghosh P. Chondroprotective drugs and osteoarthritis. Ann Rheum Dis 1990; 49: 338-9.

11 Ghosh P, Brooks P. Chondroprotection exploring the concept. F Rheumatol 1991; 18: 161-6.

12 Ghosh P. Anti-rheumatic drugs and cartilage. Baillieres Clin Rheumatol 1988; 2: 309-38.

13 Herman J H, Appel A M, Khosla R C, Hess E V. The in vitro effect of select classes of nonsteroidal antiinflammatory drugs on normal cartilage metabolism. I R heumatol 1986; 13: 1014-8.

14 Palmoski M J, Brandt K J. Aspirin aggravates the degeneration of canine joint cartilage caused by immobilization. tion of canine joint cartilage caused
Arthritis Rheum 1982; 25: 1333-42.

15 Brandt $K \mathrm{D}$. Effects of nonsteroidal anti-inflammatory drugs on chondrocyte metabolism in vitro and in vivo. $\mathrm{Am} \mathcal{F} \mathrm{Med}$ 1987; 83: 29-34

16 Muir H, Carney S L, Hall L G. Effect of tiaprofenic acid and other NSAIDs on proteoglycan metabolism in articular cartilage explants. Drugs 1988; 35 (suppl 1): 15-23.

17 Collier S, Ghosh P. Evaluation of the effects of antiarthritic drugs on the secretion of proteoglycans by lapine chondrocytes using a novel assay procedure. Ann Rheum Dis 1989; 48: $372-81$.

18 Langenskiold A, Michelsson J-E, Videman T. Osteoarthritis of the knee in the rabbit produced by immobilization. Attempts to achieve a reproducible model for studies on Attempts to achieve a reproducible model for studies on
pathogenesis and therapy. Acta Orthop Scand 1979; 50: patho 14 .

19 Golding J C, Ghosh P. Drugs for osteoarthrosis. I. The effects of pentosan polysulphate (SP54) on the degradation and loss of proteoglycans from articular cartilage in a model of osteoarthrosis induced in the rabbit knee joint by immobilization. Current Therapeutic Research 1983; 33: 173-84.

20 Pearce R H, Mathieson M H. Quantitative isolation of purified acidic glycosaminoglycans from rat skin. Can $\mathcal{F}$ Biochem 1976; 45: 1565-76.

21 Blumenkrantz N, Asboe-Hansen G. New method for quantitative determination of uronic acids. Anal Biochem 1973; 54: 484-89.

22 Farndale R W, Sayers C A, Barrett A J. A direct spectrophotometric microassay for sulfated glycosaminoglycans in
cartilage cultures. Connect Tissue Res 1982; 19: 247-48.

23 Oegema T R Jr, Hascall V C, Eisenstein R. Characterization of bovine aorta proteoglycan extracted with guanidine of bovine aorta proteoglycan extracted with guanidine hydrochloride in the prese
Chem 1979; 254: 1312-8.

24 Bushell G R, Ghosh P, Taylor T K F, Sutherland J M, Braund $K$ G. The effect of spinal fusion on the collagen and proteoglycans of the canine intervertebral disc. $\mathcal{F}$ Surg Res 1978; 25: 61-9.

25 Cole T-C, Ghosh P, Taylor T K F. Variations of the proteoglycans of the canine intervertebral disc with ageing. Biochim Biophys Acta 1986; 880: 209-19.

26 Smith P K, Krohn R I, Hermanson G T, et al. Measurement of protein using bicinchoninic acid. Anal Biochem 1985; 150: 76-85.

27 Heinegård D. Extraction, fractionation and characterization of proteoglycans from bovine tracheal cartilage.' Biochim of proteoglycans from bovine trac
Biophys Acta 1972; 285: 181-92.

28 Videman T, Michelsson J-E, Langenskiold A. The development of radiographic changes in experimental osteoarthritis provoked by immobilization of the knee in rabbits. IRCS Medical Science 1977; 5: 68 .

29 Michelsson J E. The effect of ibuprofen on the thickening, stiffening and development of degenerative changes in the rabbit knee following immobilization. Scand $\mathcal{F}$ Rheumato 1980; 9: 141-4.

30 Videman T. Experimental osteoarthritis in the rabbitcomparison of different periods of repeated immobilization. Acta Orthop Scand 1982; 53: 339-47.

31 Candolin T, Videman T. Surface changes in the articular cartilage of rabbit knee during immobilization. A scanning cartilage of rabbit knee during immobilization. A scanning electron microscopic study of experimental osteoarthritis.

32 Michelsson J E, Hunneyball I M. Inflammatory involvement in rabbit knee following immobilization and resulting in osteoarthritis. Scand $\mathcal{F}$ R heumatol 1984; 13: 273-81.

33 Videman T, Eronen I, Friman C. Glycosaminoglycan 
metabolism in experimental osteoarthritis caused by immobilization: the effects of different periods of immobilization and follow-up. Acta Orthop Scand 1981; 52 $11-21$.

34 Caterson B, Lowther D A. Changes in the metabolism of the proteoglycans from sheep articular cartilage in response mechanical stress. Biochim Biophys Acta 1978; 540: 412-22.

35 Palmoski M, Perricone E, Brandt K D. Development and reversal of a proteoglycan aggregation defect in normal canine knee cartilage after immobilization. Arthritis $R$ heum 1979; 22: 508-17.

36 Eronen I, Videman T. Effects of sodium diclofenac on glycosaminoglycan metabolism in experimental osteoglycosaminoglycan Scand 7 Rheumatol $1985 ; 14: 37-42$.

37 Videman T, Eronen I, Friman C, Ahtiala K, Mattila M J. Effects of indomethacin on glycosaminoglycan metabolism Effects of indomethacin on glycosaminoglycan metabolism in the development of experimental osteo

38 Pelletier J-P, Cloutier J M, Martel-Pelletier J. In vitro effect of tiaprofenic acid, sodium salicylate and hydrocortisone on the proteoglycan metabolism of human osteoarthritic cartilage. F R heumatol 1989; 16: 646-55.

39 Martel-Pelletier J, Pelletier J P. Molecular basis for the action of tiaprofenic acid on human osteoarthritic cartilage degradation. Semin Arthritis Rheum 1989; 18 (suppl 1): 19-26.

40 Ghosh P, Holbert C, Read R, Armstrong S, Wilson D. Chondroprotection and NSAIDs. Lancet 1991; 337: 1612-3.

41 Ghosh P, Golding J. Drugs for osteoarthrosis. II. The effects of Arteparon on proteoglycan aggregation and loss from of Arteparon on proteoglycan aggregation and loss from
articular cartilage in a model arthropathy in the rabbit. articular cartilage in a model arthropathy in

42 Burkhardt D, Ghosh P. Laboraiory evaluation of antiarthritic drugs as potential chondroprotective agents. Semin Arthritis Rheum 1987; 17 (suppl 1): 3-34.

43 Rejholec V. Long term studies of antiosteoarthritic drugs: an asessment. Semin Arthritis Rheum 1987; 17 (suppl 1): $35-53$.

44 Deraedt R, Benzoni J, Delvallee F. Pharmacological profile of tiaprofenic acid. Rheumatology 1982; 7: 78-87.

45 Daymond T J, Rowell F J. Reduction of prostaglandin-E2 concentrations in synovial-fluid of patients suffering from rheumatoid-arthritis following tiaprofenic acid or indomethacin treatment. Drugs 1988; 35 (suppl 1): 4-8

46 Vignon E, Mathieu P, Couprie N, et al. Effects of tiaprofenic acid on interleukin-1, phospholipase A2 activity, prostaacid on interleukin-1, phospholipase A2 activity, prosta-
glandins, neutral protease, and collagenase activity in glandins, neutral protease, and collagenase activity in
rheumatoid synovial fluid. Semin Arthritis Rheum 1989; 18 (suppl 1): 11-5.
47 Lewis G P. Immunoregulatory activity of metabolites of arachidonic acid and their role in inflammation. $\mathrm{Br}$ Med Bull 1983; 39: 243-8.

48 Malemud C, Sokoloff $L$. The effect of prostaglandins on cultured lapine articular cartilage. Prostaglandins 1977; 13: 845-59.

49 Kunkel S L, Chensue S W, Phan S H. Prostaglandins as endogenous mediators of interleukin 1 production. F Immunol 1986; 136: 186-92.

50 Knudsen P J, Dinarello C A, Strom T B. Prostaglandins post transcriptionally inhibit monocyte expression of interleukin 1 activity by increasing cyclic adenosine monophosphate. f Immunol 1986; 137: 3189-94.

51 Kunkel S L, Spengler M, May M A, Spengler R, Larrick J, Remick D. Prostaglandin E regulates macrophage-derived tumour necrosis factor gene expression. 7 Biol Chem 1988 ; tumour necrosis

52 Hart $P$ H, Whitty G A, Piccoli D S, Hamilton J A. Control by IFN- $\gamma$ and $P G E_{2}$ or TNF $\alpha$ and IL-1 production by human monocytes. Immunology 1989; 66: 376-83.

53 Sedgwick J B, Berube M L, Zurier R B. Stimulus-dependent inhibition of superoxide generation by prostaglandins. Clin Immunol Immunopathol 1985; 34: 205-15.

54 Dingle J T. Cartilage maintenance in osteoarthritis-interactions of cytokines. NSAID and prostaglandins in articular-cartilage damage and repair. $\mathcal{F}$ Rheumatol $1991 ; 18$ (suppl 28): $30-7$.

55 Hayns D R, Wright P F, Whitehouse M W, Vernon-Roberts $B$. The cyclo-oxygenase inhibitor piroxicam, enhances B. The cyclo-oxygenase inhibitor piroxicam, enhances cytokine-induced lymphocyte proliferation

56 Tyler J A, Saklatvala J. Pig interleukin 1 (catabolin) induces resorption of cartilage proteoglycan and prevents synthesis of proteoglycan and collagen. Br $\mathcal{J}$ Rheumatol 1985; 24 (suppl 1): 150-5.

57 Saklatvala J, Sarsfield S J. How do interleukin 1 and tumour necrosis factor induce degradation of proteoglycan in cartilage? In: Glauert A M, ed. The control of tissue damage. Amsterdam, NY, Oxford: Elsevier, 1988: 97-108.

58 Bates E J, Lowther D A, Handley C J. Oxygen free radicals mediate an inhibition of proteoglycan synthesis in cultured articular cartilage. Ann Rheum Dis 1984; 43: 462-9.

59 Michelsson J-E. Effect of acetyl salicylic acid on thickening of the rabbit knee following immobilization. IRCS Medical Science 1979; 7: 37 .

60 Daymond T J, Herbert R. Simultaneous bioavailability of tiaprofenic acid (Surgam) in serum and synovial fluid in patients with rheumatoid arthritis. Rheumatology 1982; 1: 188-93. 